\title{
Stroke in Sri Lanka: remedies for recovery
}

\author{
Padma Gunaratne ${ }^{1}$
}

Journal of the Ceylon College of Physicians, 2011, 42, 3-10

Members of the Board of Trustees, Past Presidents, Members of the Council, Fellows and Members of the Ceylon College of Physicians, distinguished invitees, ladies and gentlemen,

It is with deep humility and pride that I make the presidential address at the induction ceremony of the 44th President of the Ceylon College of Physicians. The CCP is the supreme body that represents the academic development of physicians in Sri Lanka. As its newly inducted President, I have an enormous task ahead of me to follow in the footsteps of my senior colleague and predecessor, Dr. Kamani Wanigasuriya; an outstanding physician who carried out an excellent academic programme in 2010 . Her contributions in organizing the Training of Trainers Programme and a Symposium in Geriatrics during the Annual Sessions made a deep impact on medical training and medical practices in this country. On behalf of the newly appointed Council of the College, I wish to express our sincere gratitude to the Past President and her Council for their excellent work and contributions throughout 2010.

The Ceylon College of Physicians was founded following an informal discussion by 11 physicians at the Consultants' Lounge of the General Hospital, Colombo, on 25th of July $1967^{1}$. Since then it has grown from strength to strength and functions as a responsible academic body providing multi-faceted educational programmes of the highest quality for physicians and trainee physicians assisting their educational needs. It also plays an advocacy role as the main stakeholder that advises the Ministry of Health in formulating health policy, prioritizing health delivery based on changing needs of society and in implementing health systems in an organized, integrated and meaningful manner throughout our island nation. My sincere belief is that at present, our College could be proud to be on par with most well recognized and long-standing colleges of developed countries, with strong collaboration in postgraduate training.

\footnotetext{
${ }^{1}$ Consultant Neurologist, National Hospital of Sri Lanka, Colombo; President, Ceylon College of Physicians 2011.
}

It is an ardent task to be leading the College of Physicians. Keeping with its long standing traditions, I with the help of the Council have planned to organize a most attractive programme for this year on the theme "Beyond All Limits". Nothing would contain us in discharging our responsibilities to uphold standard of care for our island nation. In addition to the Annual Scientific Sessions scheduled to be held from 15th 17th September, there will be inaugural foundation sessions organized aiming the needs of outstation physicians. The College will be conducting a special programme on cost effective interventions on prevention, and control of non-communicable diseases to primary health care doctors and a workshop on stroke rehabilitation in collaboration with the National Stroke Association of Sri Lanka for nurses from Northern Province. Among other activities planned are teaching programmes paying attention on postgraduate training, programmes aiming the improvement of research skills and building leadership qualities of doctors. Along with my capable and committed Council, I look forward to follow the footsteps of our predecessors in sustaining the responsibilities of this high office.

On this occasion of the induction of the President, it is customary for the newly inducted President to address the membership on an important medical issue that requires specific attention. I thought it is most appropriate to highlight the reality of a day to day common clinical problem on this special occasion. In my opinion it is a real burning medical issue for our nation and an issue that has been so close to my heart over the last several years.

\section{Stroke in Sri Lanka: remedies for recovery}

According to WHO publication, "Global Health Risks; Mortality and Burden of Disease Attributable to Selected Major Risks", cardio-vascular disease accounts for $30 \%$ of deaths world wide ${ }^{2}$. Out of these, 5.7 million deaths, which is $9.7 \%$ of all deaths is caused by stroke. It becomes second only to deaths caused by ischaemic heart disease and cancers. We live in a region with a high prevalence and incidence of cardiovascular disease. Fast ageing population further increases the prevalence of stroke. The strategies implemented in developed countries have effectively 
All events

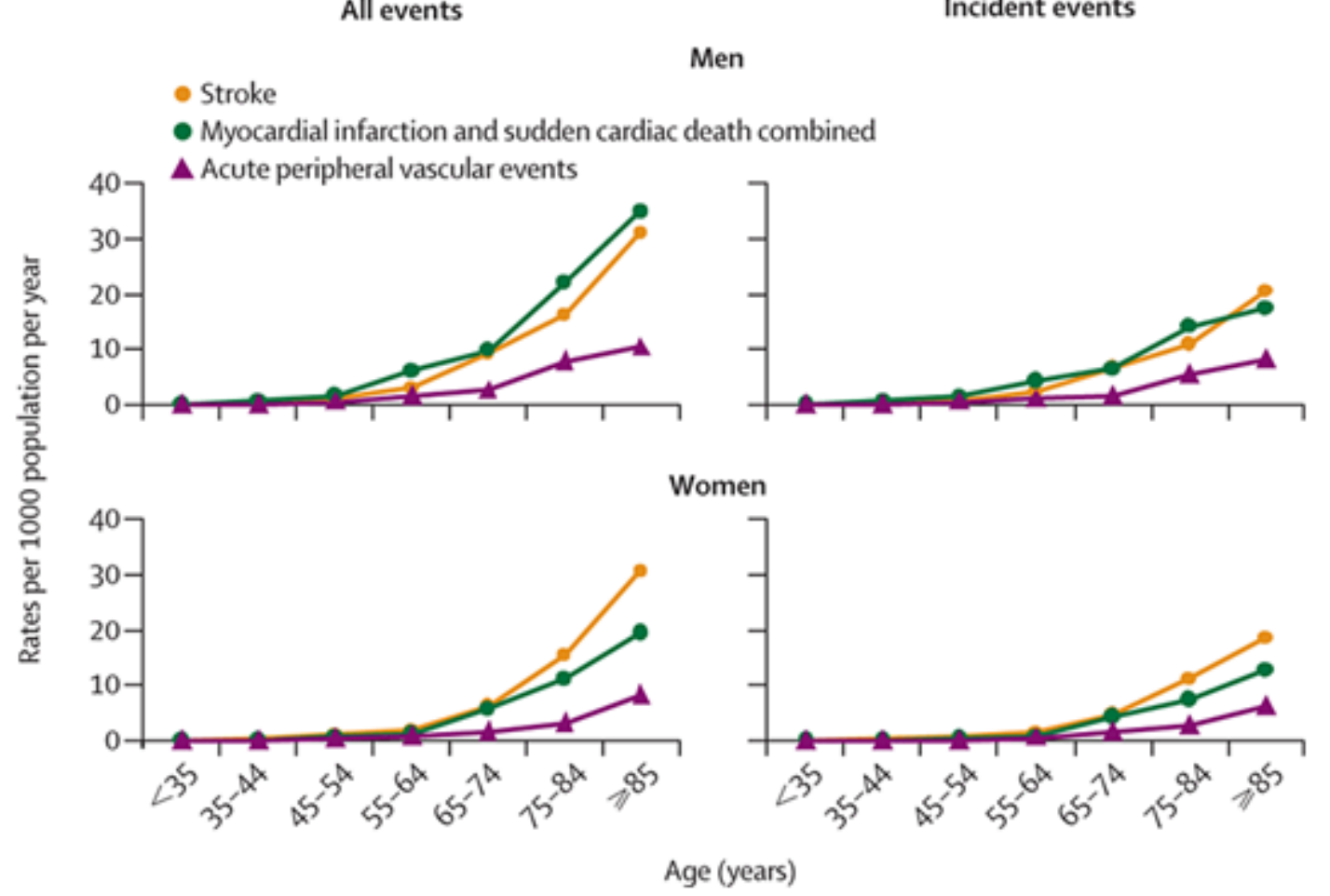

Figure 1. Age specific incidence of stroke, myocardial infarction and acute peripheral vascular events.

controlled the incidence of this disease ${ }^{3}$. According to Feigin et al, on time trends in stroke from 1970 to present, published in Lancet Neurology shows a $42 \%$ decrease in stroke incidence in high income countries while the rate has become more than double in low middle income countries. The incidence in low middle income countries is now exceeding that of the high income countries. According to Rothwell et al the age specific incidence of stroke, myocardial infarction and peripheral vascular disease are more or less equal (Figure 1$)^{4}$. These figures clearly signify the relevance of implementation of accepted standard care for stroke while paying maximum attention for primary and secondary prevention of the disease.

\section{Life following a stroke}

There are numerous misconceptions about life following a stroke especially with regard to rehabilitation, both in the general population and among health care providers. In some respects it depends on personal perspective in terms of interpreting the data. For instance, consider the well known saying that an optimist views 12 ounce glass containing 6 ounces of water as half full where as pessimist views it as half empty. Given the influence of perspective what does the stroke recovery data show? In general, of those patients who survive their stroke, 10 - $15 \%$ will recover completely, 25 - 30\% will recover with minor impairment, 35 - 40\% will experience moderate to severe impairment and $10-15 \%$ will be bedbound at the end of 1 year. From the "glass is half empty perspective", one could conclude that stroke is the leading cause of disability and more than half of stroke survivors will end up severely impaired. But one could more optimistically interpret this data as stating that nearly half of stroke survivors have few or no deficit at one year after their stroke; that is stroke is not only survivable but there is life after stroke.

\section{How should stroke be treated?}

There is good evidence from multiple, randomized controlled trials from many countries that stroke is best managed in stroke units. The number of deaths and dependency avoided by treating thousand patients with aspirin is 23 , thrombolysis is 15 and for treating stroke with stroke unit care is 107 . Therefore, the best form of treatment for stroke that emerged over last several decades is stroke unit care.

\section{What is a stroke unit?}

Stroke unit is a ward or defined area where patients with stroke are admitted and may remain for a variable time to be diagnosed, treated, and 
rehabilitated by a dedicated multidisciplinary team that include trained medical officers, nurses, physiotherapists, occupational and speech therapists, social workers and counselors.

At the beginning of 2011, there were meager facilities available for stroke patients, only two established stroke units accommodating 30 beds, in Sri Lanka. In general, $10 \%$ of stroke victims would die within the 1st month following the stroke while $90 \%$ survive. Majority who die as a direct result of stroke would die within the first two weeks. A significant proportion of deaths that occur afterwards are caused by complications that are preventable if proper care is instituted. Majority of stroke patients in Sri Lanka have left hospitals by the time they develop complications. They leave hospitals leaving beds in medical wards for other patients who are considered to have more important disease entities.

Once discharged from medical wards prematurely what are the available options for these disabled patients? They are expected to be brought for physiotherapy as outdoor patients. Difficulties in transporting an ill, disabled patient for therapies restrict majority continuing treatment from hospitals. They lose faith with our system and search for alternative forms of treatment.

Table 1. Behaviour with regard to alternative medicine (AM)

\begin{tabular}{lcc}
\hline & NHSL & Galle, Kalutara and Ratnapura \\
\hline Total number of patients & 96 & 62 \\
Percentage of males & $52 \%$ & $64.5 \%$ \\
Mean age & $54.3 \pm 13.6$ & $61.6 \pm 10.3$ \\
Age range & $14-78$ years & $14-78$ years \\
$\%$ sought AM & $31 \%$ & $54.8 \%$ \\
\hline
\end{tabular}

Table 2. Results of analysis of alternative medicine group

\begin{tabular}{lcc}
\hline & NHSL & Galle, Kalutara and Ratnapura \\
\hline $\begin{array}{l}\text { \% sought AM after being treated at } \\
\text { hospitals that practise western medicine }\end{array}$ & $96.6 \%$ & $94.1 \%$ \\
& & \\
Type of AM & & \\
$\quad$ Ayurveda & $76.6 \%$ & $85.3 \%$ \\
Traditional & $20.3 \%$ & $14.7 \%$ \\
Accupuncture & $3.3 \%$ & \\
& & \\
Type of treatment & & $76.4 \%$ \\
Decoction & $46.7 \%$ & $32.3 \%$ \\
Application of grounded herbs & $23.3 \%$ & $97 \%$ \\
Application of herbal oils & $86.7 \%$ & $41.1 \%$ \\
Manipulation & $26.6 \%$ & $32.3 \%$ \\
Tablets & $11.8 \%$ & \\
Acupuncture & $5.8 \%$ & $11.8 \%$ \\
Any other & & \\
\hline
\end{tabular}


Premature discharge from hospitals; is that the only reason to seek for alternative medicine?

We carried out a descriptive study to find out behaviour with regard to alternative medicine among stroke patients. We interviewed 96 patients attending the Stroke Clinic at National Hospital of Sri Lanka and 62 patients attending Neurology Clinics at Galle, Kalutara and Ratnapura General Hospitals (Table 1). Mean duration of hospital stay for stroke unit patients treated in Stroke Clinic was 19 days while the same for outstation patients was 7 days. Our study revealed more than $30 \%$ of stroke patients treated at Stroke Clinic, National Hospital and 54\% of outstation patients had sought the help of alternative forms of medicine. It was interesting to note that more than $90 \%$ had sought alternative medicine after leaving our own hospitals. The form of alternative medicine sought by majority is ayurveda (by 76\% from NHSL and $85 \%$ from outstations) (Table 2). Most popular form of treatment was application of herbal oil. Decoctions and tablets or guly are other commonly used medications. Sixty six percent from NHSL and $88 \%$ from outstation believed that the alternative medicine was beneficial. However, it was disturbing to note that $10 \%$ from National Hospital and 29\% from outstation hospitals had stopped medicine given for secondary prevention while on alternative medicine. It is important to realize that these are the data of patients attending hospital clinics and some others do not visit hospitals at all.

\section{Why do they seek alternative medicine? Is it inexpensive?}

Consultation was free of charge for $42 \%$ while it ranged from Rs 200 - 1000 rupees for others. However, the total cost for treatment ranged from $3500-75,000$ rupees. These findings influenced me to look more into various types of alternative medicine and their practices available in Sri Lanka.

\section{What are the types of alternative medicine available for stroke patients in Sri Lanka?}

Majority of the stroke patients had sought ayurveda and indigenous medicine as alternative forms of treatment. Acupuncture and homeopathy are other forms of alternative medicine available in the island. Use of pigeon's blood for massage, reiki therapy, IV fluids in villages, and opium are some other forms of alternative medicine practiced in Southern India. None from the examined sample had sought these forms of treatment.

\section{Traditional medicine}

The earliest system of medicine that prevailed in Sri Lanka was Deshiya Chikitsa which was the truly indigenous system of medicine that was handed down from generation to generation. There is a belief that the statue by the bank of Prakrama Samudra belongs to Rishi Pulasthi or Pulasthi Isiwara who was the grandfather of King Rawana. The presence of a brahmanical sacred thread that runs from the left shoulder across the body and the ola leaf book that he carries confirms that it is of Rishi Pulasthi. It is believed that Pulasthi Isiwara was the founder of indigenous medicine. Since technology for printing was not available, for the convenience of memorizing, most of literature on indigenous medicine was available in verses inscribed on ola leaves.

The concept of traditional medicine was that it is a system of natural medicine. Nature is the best medicine. It respects and utilizes nature's power of healing. It follows nature's laws and theories in terms of health. According to traditional medicine there are no diseases but only sick people. It uses natural resources and adopts a holistic and multidisciplinary approach.

In traditional medicine physicians used medicine for physical problems and expected cure as out come. Exorcists performed rituals as psychological support for mental problems and expected harmony as outcome. Monks introduced religion for moral support for spiritual aspect and expected tranquility. There were ceremonies with cultural values to bring on blessings. Predictions were made by astrologers to plan the future happenings. Majority of people still adopt most of these therapy techniques. These techniques are still being used in traditional medicine for treatment of stroke.

\section{Ayurveda}

Ancient ayurveda was introduced to Sri Lanka from North India. It was a part of the cultural heritage that flowed in to the country in the 3rd century BC with the arrival of Mihindu thero. Ayurveda at that time thrived with the royal patronage of the kings who ruled the country. This is well evident by the ruins of hospitals and the medicinal tubs for sick, present in archaeological sites in Auradhapura, Mihintale, Madirigiriya, Dighavapi and Maligavila.

From 16th Century onwards, with the foreign invasions by the Portuguese and the Dutch, there was a rapid decline of ayurveda practices along with our ancient arts and crafts. The worst period for ayurveda in Sri Lanka was the British era when ayurveda had to compete with western medical practices. What we enjoy today is what was established with the advent of British in Sri Lanka.

Ayurveda available today is an integrated system of traditional medicine, ayurveda from North India, 
Siddha from South India and Unani from Middle East countries.

\section{The concepts in ayurveda and the type of} treatment practiced for stroke patients

According to concepts in ayurveda, everything in universe including human is made up of Panchamahabutha or 5 elements; Prithvi, App, Teja, Vayu and Akasha. Patavi or Prithivi is hardness, App or jala is water or moisture, Teja is fire or heat energy, Vayu is air or movement and Akasha is space or cavity.

Every atom in the universe can be regarded as representing panchamahabuthas. Proton and neutron in the atom gives hardness and certain weight. Electron, proton and neutrons are held together by the force of cohesion or app. Teja represents the latent energy in the atom and vayu, the movement of electrons in the atom. Akasha represents the space in which the electrons move in the atom.

In ayurveda the combination of these 5 elements form thri-dosha or three biological humors and sapthadhatu which describes the physiology of organisms. Vatha, pitha and kapha are thri-doshas and the combination of these form the natural body composition of the individual that he is born with. Imbalance of thri-doshas causes individuals to fall ill. There are many reasons for imbalances of thri-doshas.

According to ayurveda there are 80 vatha disorders and stroke is one of them. The treatment of stroke in ayurveda is divided into 3 phases. Those are purification, pacification and restoration. The treatment procedures are determined by many factors including age, gender, duration of stroke, whether the attack occurred in day or night, presence of other diseases, body composition of the patient with regard to vatha, pitha and kapha, and the climate. Majority of acute stroke with dysphagia, bladder involvement and altered level consciousness at present are not treated, but directed to government hospitals that practice western medicine. In majority of situations insertion of urinary catheters and naso-gastric tubes are not attempted, but tube feeding and managing patients with urinary catheters are carried out.

First two phases of management, i.e. purification and pacification is done using varying forms of decoctions, paste and oil prepared mainly out of herbs. The type of treatment is determined by the condition of the patient, natural body composition of the patient and the stage of the stroke. If the patient's condition is serious pacification with decoctions is carried out without purification. Once the patient's condition is better oil applications are commenced. Oil applications are carried out either as sarvangadhara or applying oil all over the body or shirodhara or applying oil on the head. The type of oil and thickness of oil is determined depending on the condition of the patient. The whole body is massaged using oil by trained masseurs. This is followed by physiotherapy for limbs that are directed along the direction of limb movements.

The last phase of treatment is restoration phase. The patient is given more rejuvenation form of treatment that might carry more nutritional constituents over this period. The patient may be given a medicinal milk bath or massage with bundles made using medicinal milk rice wrapped in soft cloth during this phase of treatment.

Selected patients who are strong enough may undergo selected form of punchakarma during this phase of treatment. punchakarma includes nasna or introducing liquid medicine through the nostrils, vomiting, purgation, enema and bloodletting therapy. Out of these treatment procedures ones that are applicable to stroke patients would be enema and Nasna.

In the long-term, application of oils for affected limbs and decoctions for systemic symptoms are available.

\section{Facilities available for ayurveda treatment}

There are about 3,000 beds in government sponsored ayurveda hospitals in Sri Lanka. About 70\% of these beds are occupied by stroke patients. All immobile patients are offered inward care and mean duration of hospital stay is about 2 - 3 months.

There are no reported controlled trials to support effectiveness of any of the ayurveda treatment procedures.

\section{Acupuncture}

Acus in Latin is needle, pungere is puncture or pricking. Pricking on selected points with a small needle is acupuncture. This is an ancient Chinese medical practice that could be traced as far back as the 1st millennium BC. In contrast to ayurveda, acupuncture is better established in western countries and one could find 397 publications in Medline for acupuncture in stroke. Nevertheless, in view of invasive nature of the technique, it is difficult to carry out double blind controlled studies with acupuncture.

\section{Concepts of acupuncture}

Long ago, Chinese discovered that there were certain points of the body which if massaged, 
punctured, heated or burnt, it relieved pain or had a beneficial effect for certain disorders. Further it was revealed that by stimulation of widely separated points it was possible to influence the functioning of specific internal organs. These points were systematically arranged on the basis of the representing organ and those systematic arrangements were named as channels.

In the body surface there are twelve regular channels called twelve paired channels. Each regular channel relates to an internal organ. The organs are divided as yin or solid and yang or hollow organs. Out of the twelve regular channels that represent twelve organs six are called yin channels that represent solid organs and six are called yang channels that represent hollow organs. Each yin organ and channel is paired with a yang organ and channel.

The ancient Chinese believed that vital energy flowed in the twelve paired channels in a precise cyclic sequence. According to their thoughts vital energy flowed from lung to large intestine to stomach to spleen to heart to small intestine to urinary bladder to kidney to pericardium to san jiao or triple energizer to gall bladder to liver and back to lung. According to acupuncture theory, healthy state is characterized by a dynamic balance between the yin and yang of the body and an unhealthy state is characterized by some imbalance between the yin and yang of the body. Basic treatment is aimed at filling up deficient yin or yang.

According to Chinese traditional medicine brain is an extraordinary organ and spirit is located in the brain. Heart, brain and pericardium acts as a one functional unit. In treating brain disorders, there is no separate brain channel but believes the heart and pericardium channel could be used in addition to the channels that pass over the scalp area.

Accordingly acupuncture for stroke will be carried out on heart channel that originates its superficial course from axilla. It runs distally on the anterior and medial aspect of the arm to end near the lateral edge of the base of the nail of the little finger. Acupuncture on this channel is useful for stroke, heart diseases and many other neuropsychiatric disorders. The pericardium channel commencing just lateral to the nipple runs along the front of the upper limb and ends at the tip of the middle finger. This is another channel that could be used for treatment of stroke. In addition, several other channels that run over the scalp could be used on stroke patients.
Stroke patients develop speech, vision and sphincter disturbances in addition to the paralysis of limbs. The recommended acupuncture for speech difficulties following paralytic stroke is extremely frightening. It is recommended to prick the region of atlanto-axial joint along the direction of chin while the neck is kept in flexed position.

For acupuncturists acupuncture procedure is simple, safe, effective and economical. Needle has to be sterile. Some centres perform only needle pricks while in some other places needles are electrically stimulated using stimulators. In some centres it is followed by varying physiotherapy techniques. According to literature in acupuncture, the mechanism of acupuncture is the physiology of endorphins and related chemicals. There is some scientific evidence that when individuals suffering from chronic pain are treated with acupuncture, endorphins are released into the cerebrospinal fluid and the endorphins peak at the time when the analgesic effect of acupuncture is most pronounced.

\section{Scientific evidence on acceptance and use of acupuncture on stroke rehabilitation}

A Canadian study done in a group of population to find out whether acupuncture is acceptable to stroke patients revealed $87 \%$ Canadian stroke patients would consider acupuncture as a treatment option ${ }^{5}$. A meta analysis of 25 databases and 12 major Korean traditional medicine journals on randomized controlled clinical trials revealed no benefits of acupuncture as a treatment for functional recovery after stroke ${ }^{6}$.

\section{Homeopathy}

Advertisements on homeopathy treatment are not uncommon in Colombo and other cities in Sri Lanka. Homeopathy is a method of treating diseases with small amounts of remedies that in large amounts in healthy people produce symptoms similar to those being treated. It was proposed by German physician Samuel Hahnemann in 1796. Homeopathic remedies are prepared by serial dilution and shaking by forceful striking, believing each dilution potentiates the effect.

Homeopathy's efficacy beyond the placebo effect is unsupported by the collective weight of scientific and clinical evidence. Science and Technology Committee, House of Commons, United Kingdom in 2010 concluded that homeopathy is no more effective than placebo. Use of medicines lacking active ingredients and the lack of convincing scientific evidence supporting the efficacy have caused homeopathy to loose its credibility as an effective form of treatment. 
Siddha and Unani are other forms of alternative medical practices seen in South India and Arabian countries. These practices now are mingled with others in Sri Lanka and it is difficult to recognize separately.

\section{Discussion}

Until a few decades ago stroke progress was hindered by ignorance and negativity both within and outside of the medical profession. However, recent scientific advances in stroke has made it to be one of the most dynamic and evolving fields with emerging new concepts in stroke prevention and management. The most effective form of treatment introduced over last two decades for stroke is stroke unit care by multidisciplinary teams. Treating stroke in a stroke unit avoids one more patient out of every eighteen treated, from dying or being dependant. Treating stroke in a stroke unit is likely to improve confidence of the patient on the system. Establishing stroke units are least expensive. It needs no complex and expensive technology. Therefore establishing stroke units is a need of the day and the most appropriate cost worthy form of therapy for a low middle income county like Sri Lanka. Further, it is important that the medical profession makes use of available resources to advance their knowledge to clear misconceptions. It is the obligation of health hierarchy to make incentives available for medical profession to be up to date.

It is common for stroke patient to seek help of alternative medicine. Premature discharge owing to non availability of organized form of support for acute and long term care in government hospitals that practice western medicine is an important reason that influences the stroke sufferer to seek alternative form of treatment. Unrealistic expectations of recovery and lack of faith on allopathic medicine also influence the stroke victim to leave western medicine. Cultural, social and economical factors also influence in arriving at decisions on the form of treatment sought.

Ayurveda and traditional medicine are the mostly practised form of alternative medicine in Sri Lanka. There is vast room for research in ayurveda practices. In ayurveda, therapy techniques are expensive, complex and time consuming. Ayurveda practitioner spends more time with the patient. All these cause a positive impact on the patient who is already depressed and is more concerned of the disability than secondary prevention. Mental well being is an important aspect in patient management. It is important that we appreciate this aspect of the problem and inculcate an interest to pay attention on the disability of the patient in addition to recommending medication for secondary prevention.

\section{Recommendations}

Ladies and gentlemen, the government of Sri Lanka has recognized well the impact of non communicable diseases to our nation and has allocated colossal amounts of funds to combat this situation. It is in this context I propose that there is an urgent need for establishing stroke units to maintain standard care for stroke patients treated in our hospitals.

There should be a stroke unit in all big hospitals. Availability of a stroke unit should be an indicator of the quality of care provided by that hospital. As an initial step they could be established in every province. It is recommended to establish units with 10 - 30 beds. It would need staffing with extra nurses and therapists. They could be served by the already available physiotherapy, speech therapy and occupational therapy units of those hospitals. This unit could be centred for development of other stroke related facilities such as thrombolysis for acute stroke, stroke care givers programmes, TIA clinics. This is a need of the country to tackle the second leading cause of death in people more than 50 years of age.

\section{Tribute}

Ladies and gentlemen, at this moment I wish to pay tribute to all those who have nurtured, influenced and helped me to become what I am today. In addition to support I got from my family, I am grateful to all my teachers, from my schools Dharmapala and Devi Balika, from Faculty of Medicine Peradeniya, Professorial Surgery and Medicine departments of NHSL during my internship and the teachers in postgraduate training. It is impossible to name all. A special word of appreciation is conveyed to Dr. J. B. Peiris, my teacher in neurology.

\section{Acknowledgement}

Ayurveda

- Dr. Watsala Wijesingha, Postgraduate Student studying in India

- Dr. Wimal Karunaratne, Ayurveda Hospital Anuradhapura

- Dr. Tennakoon, Director, Ayurveda Hospital

- Dr. H. A. S. M.Gunasekara

- Dr. H. A. Thilaka Malani

- Dr. Indra Fonseka

- Dr. P. D. Seeladari

- Dr. K. S. R. Fernando

- Masseur Dhamawardana

- Masseur Sarath

- Other staff in Ayurveda Hospital 
Consultant Neurologists

- Dr. Geetanjana Mendis

- Dr. Arjuna Fernando

- Dr. Senaka Bandusena

- Prof. K. D. Pathirana

- Dr. V. T. Rajendiran

- Dr. Jeyaraj Pandian, Neurologist, India

Others

- Dr. Jeevatharan Hamsananthy

- Dr. Lanka Alagiyawanna

- Miss. Renu, Counselor, NHSL

\section{References}

1. Hand Book 2007, Ceylon College of Physicians.
2. WHO. Global Health Risks Mortality and Burden of Disease Attributable to Selected Major Risks.

3. Feigin VL, Krishnamurthi R. Public health strategies could reduce the global stroke epidemic. Lancet Neurology 2010; 9: 847-8.

4. Rothwell PM. Lack of epidemiological data on secondary stroke prevention. Lancet Neurology 2005; 4: 518-9.

5. Yam W, Wilkinson JM. Is acupuncture an acceptable option in stroke rehabilitation? A survey of stroke patients. Complement Ther Med 2010; 18: 143-9. Epub 2010 Jun 15.

6. Sze FK, Wong E, Or KK, Lau J, Woo J. Does acupuncture improve motor recovery after stroke? A meta-analysis of randomized controlled trials. Stroke 2002; 33: 260419.

7. Ernst E, Lee MS. Acupuncture during stroke rehabilitation. Stroke 2010; 41: e549; author reply e550. Epub 2010 Jul 8. 